\section{Microscopy and Microbes at Plum Island: Protecting America's Livestock}

\author{
Thomas G. Burrage \\ Plum Island Animal Disease Center, \\ U.S. Department of Homeland Security \\ tburrage@piadc.ars.usda.gov
}

Plum Island Animal Disease Center, located on a small island off the coast of Long Island's North Fork, has been clouded in mystery and misinformation for years. Often the topic of conspiracy theorists, this secret place has generated many myths-from aliens to anthrax and pink eels to secret submarines. But the truth of the center's mission is far less colorful yet far more crucial to the state of the nation's agriculture.

In June 2003, operational responsibility for the Plum Island Animal Disease Center (PIADC) transferred from the United States Department of Agriculture (USDA) to the United States Department of Homeland Security (DHS), and PIADC became the core of the DHS effort to protect US livestock from foreign animal disease agents. (Figure 1). PIADC has been conducting research including vaccine development for foot-and-mouth disease (FMD) and other exotic animal diseases for more than 50 years. FMD is extremely contagious and infects domesticated, cloven-hoof animals such as cattle, swine and sheep and wildlife like antelope, bison, elk and deer. Accidental FMD outbreaks have recently caused catastrophic livestock and economic losses in the United Kingdom (2001) and in Taiwan (1997).

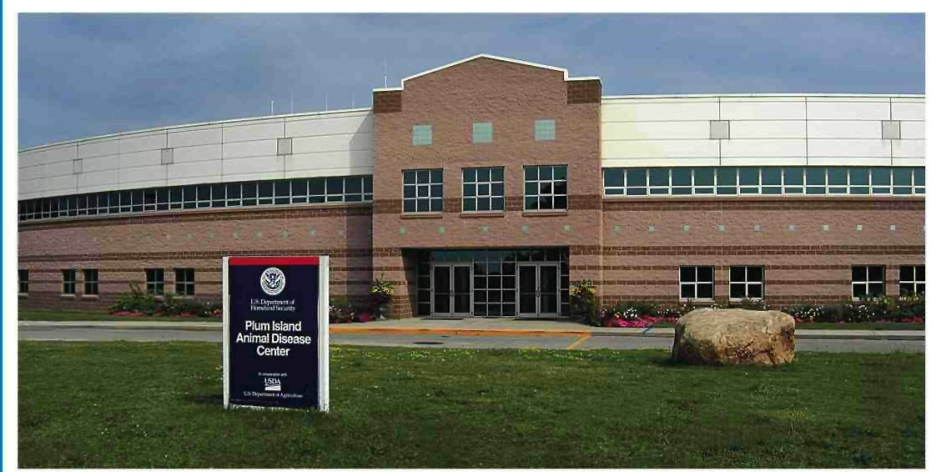

Figure 1: Plum Island Animal Disease Center, the nation's first defense against foreign animal disease.

\section{PIADC's Research Groups}

Although land, buildings and other facilities, as well as the responsibility for operating PIADC transferred from USDA to DHS, USDA's Agricultural Research Service (ARS) and Animal and Plant Health Inspection Service (APHIS) continue to maintain active research and diagnostic programs on the island. Additionally, DHS has established its own research programs at PIADC to work closely with existing USDA programs and to further the shared strategy for protection of U.S. agriculture and food.

USDA's APHIS scientists operate the Foreign Animal Disease Diagnostic Laboratory (FADDL), an internationally recognized laboratory performing diagnostic testing of samples collected from US livestock presenting with clinical signs suggestive of an exotic disease. FADDL maintains the North American FMD Vaccine Bank on behalf of the U.S., Canada and Mexico, acts as the reference laboratory for the newly established National Animal Health Laboratory Network and maintains an active training component conducted at the Foreign Animal Disease school several times a year. These schools

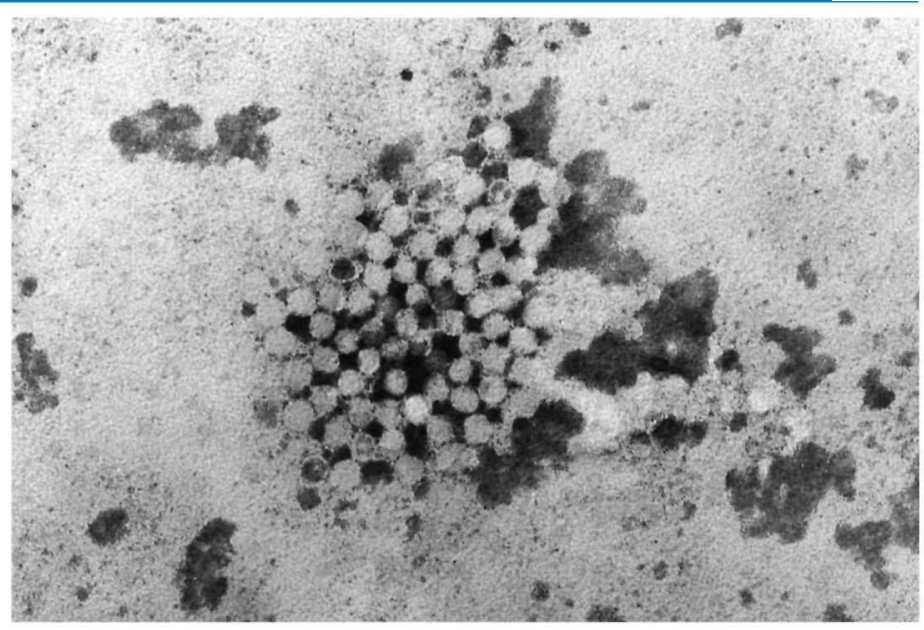
lesion.

Figure 2: Negative stain foot and mouth disease virus from mouth

give veterinarians first-hand experience recognizing and diagnosing high consequence foreign animal diseases in livestock.

USDA's ARS scientists perform both basic and applied research involving FMD, classical swine fever and vesicular stomatitis virus with the following objectives: 1 . obtain knowledge of route of infection of pathogens, method of colonization, target organs and immunopathology to create new strategies for control of livestock disease; 2 . develop new strategies to control disease epidemics; and 3. develop more sensitive and accurate methods of disease agent detection and identification.

DHS is the responsible agency for coordinating the overall national effort to enhance protection of critical infrastructure and key resources of the US, including agriculture and food. Since its inception, DHS has pursued a joint approach with the USDA to safeguard US agriculture.

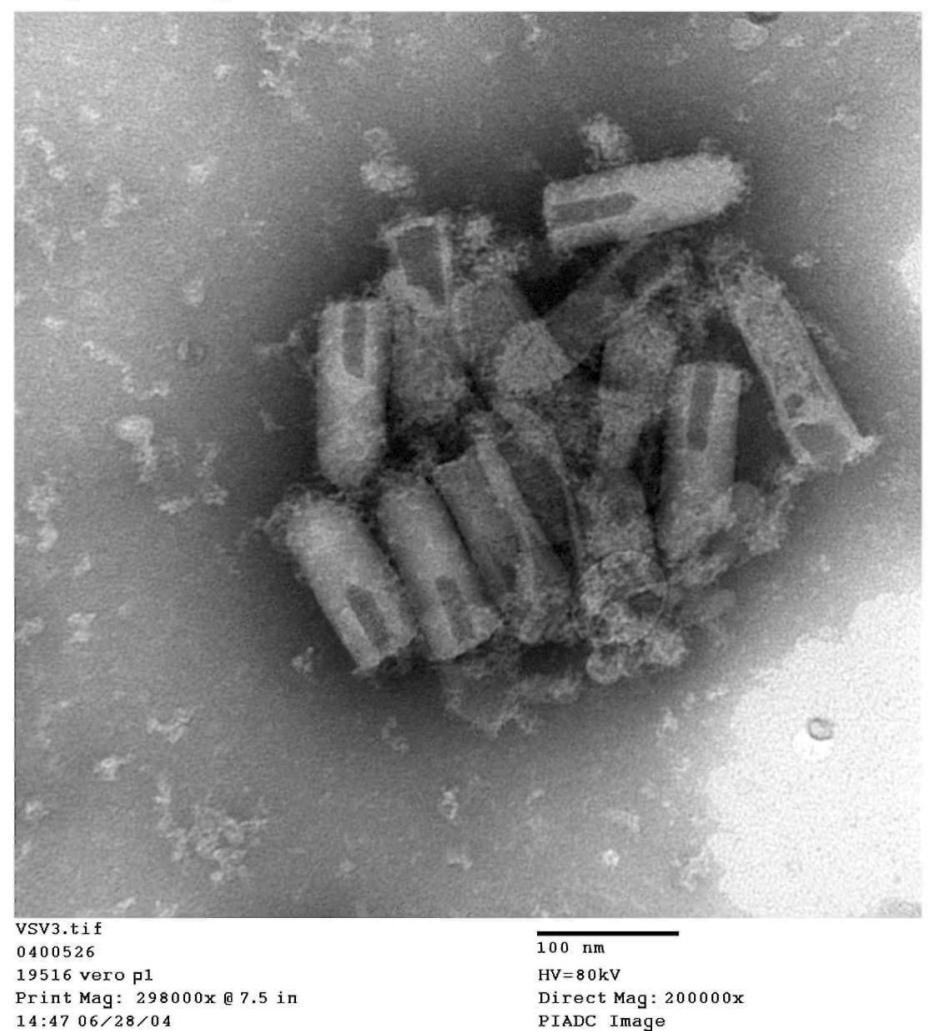

Figure 3: Negative stain vesicular stomatitis virus from tissue culture supernatant. 


\section{It's the same with}

\section{microanalysis...}

\section{you want your \\ supplier to always \\ be there for you.}

At EDAX, we take enormous pride in providing today's best microcharacterization technologies. But this is not the end. In fact, installing your system is just the beginning of your relationship with EDAX.

We are equally proud of our unparalleled global support for all our customers. EDAX provides frequent, in-depth training classes, skilled service engineers on call to assist you and scientists to advise you in your specific applications.

Next time you are in the market for X-ray microanalysis, EBSD or micro-XRF systems, come to EDAX. We will not let go of you after the sale is made.

Discover what good service and support are all about at: www.edax.com/thinkEDAX 


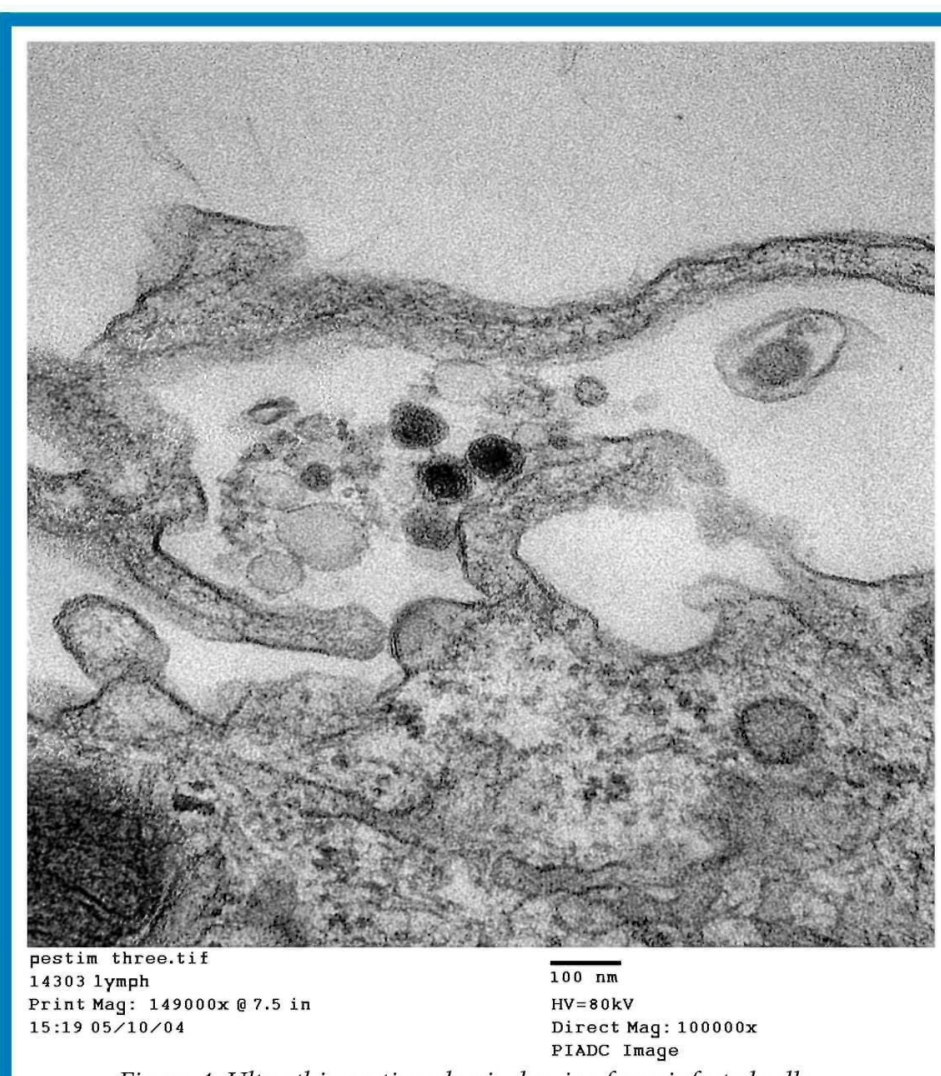

Figure 4: Ultra thin section classical swine fever infected cells

The DHS science program at PIADC is composed of three units: Targeted Advanced Development (TAD), which develops animal vaccines for USDA's National Veterinary Stockpile; Disease Assessment and Forensics, which identifies disease agents and their origins; and Core Services (CS), which provides sequencing and microscopy support.

\section{Microscopy Supports PIADC by Identifying Disease Agents}

The microscopy area, called Viral, Cellular and Molecular Imaging (VCMI), supports the three agencies by examining agents from experimentally infected animals or from fluids and tissues of suspect field cases. For example, figure 2 shows negatively stained particles aspirated from a mouth lesion of a cow inoculated with FMD virus 48 hours previously. The clumped, $25 \mathrm{~nm}$, hexagonally shaped particles are surrounded by amorphous material from the bovine saliva. The

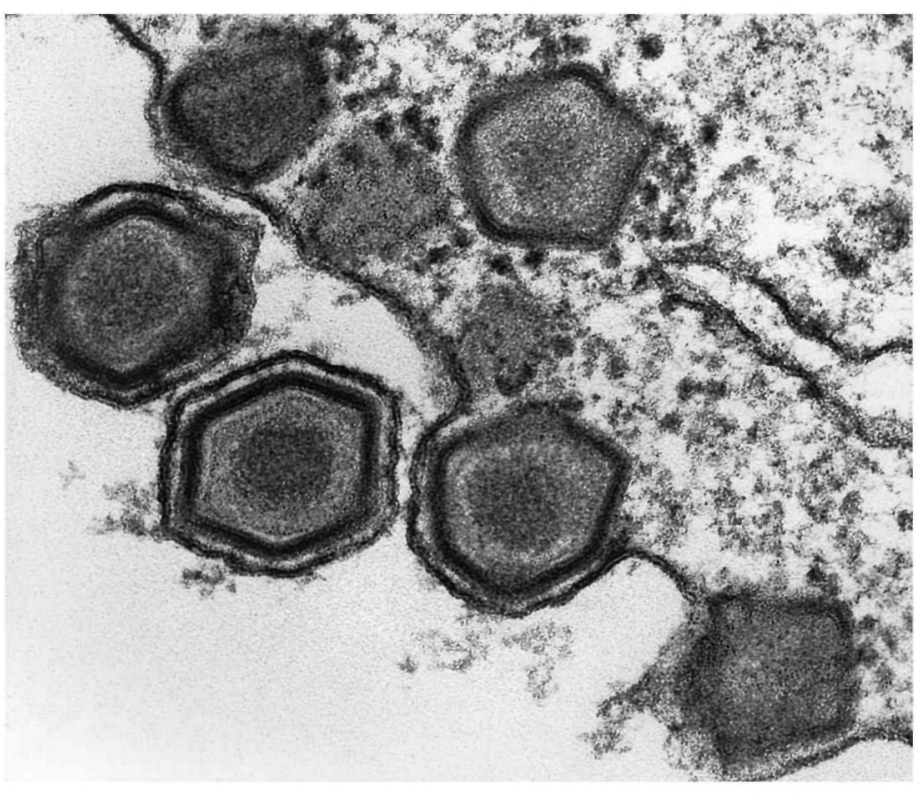

Figure 5: Ultra thin section of African swine fever infected cells. particles' small size, lack of a membrane envelope and hexagonal shape identifies them as a members the picornaviridae. In contrast, figure 3 shows $90 \mathrm{~nm}$, rod-shaped particles of vesicular stomatitis virus, which causes FMD-like lesions in cattle. The virus imaged here was responsible for a vesicular stomatitis virus outbreak in Texas in June 2004. Two other viruses, swine vesicular disease virus and vesicular exanthema of swine virus, also cause FMD-like lesions in swine, but they have different sizes and morphologies.

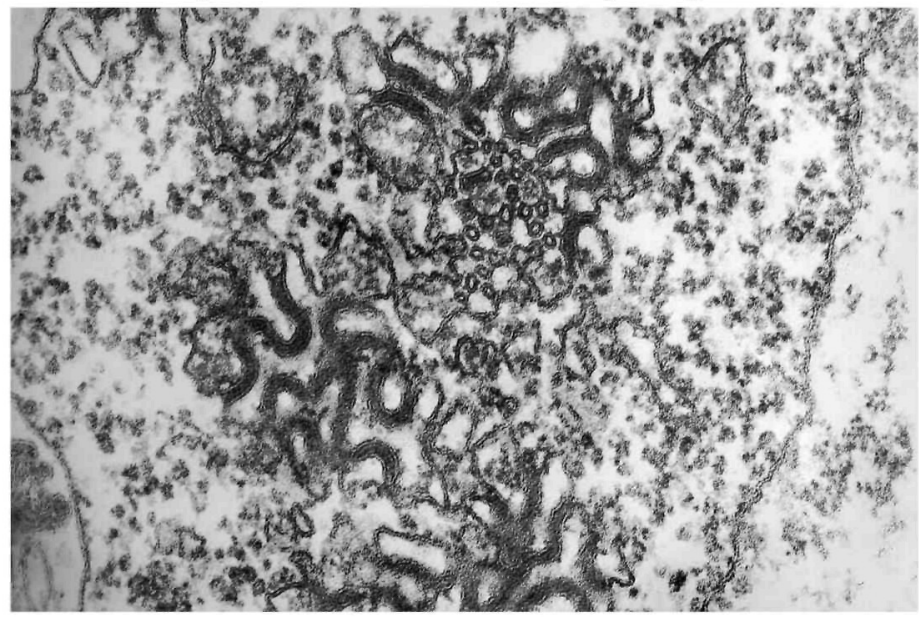

Figure 6: Thin section recombinant $2 \mathrm{C}$ antigen.

\section{Electron Microscopy-Still a Staple in Diagnoses}

Although an older technique in the diagnostic arsenal, electron microscopy provides a rapid screening tool for potential foreign animal disease cases that can be confirmed by polymerase chain reaction assays and/or nucleotide sequencing. Classical swine fever (CSF) or hog cholera and African swine fever (ASF) are foreign animal diseases that also present with similar clinical signs, so electron microscopy can be crucial to determining diagnosis. CSF virus (Figure 4 ) is currently causing outbreaks in the Caribbean, and ASF virus (Figure 5) represents a potential problem for US swine production because of growing air travel and trade between the US and the African continent. CSF is an $80 \mathrm{~nm}$ diameter, enveloped RNA virus that closely associates with infected cells (Figure 4); whereas ASF is a very large $(220 \mathrm{~nm})$ DNA virus with multiple layers (Figure 5). With microwave processing (approximately 4 hours) for preparing sectioned material, the speed for diagnosis of these exotic agents is comparable with molecular or antibody-based assays.

Because USDA's APHIS also develops reagents and di-

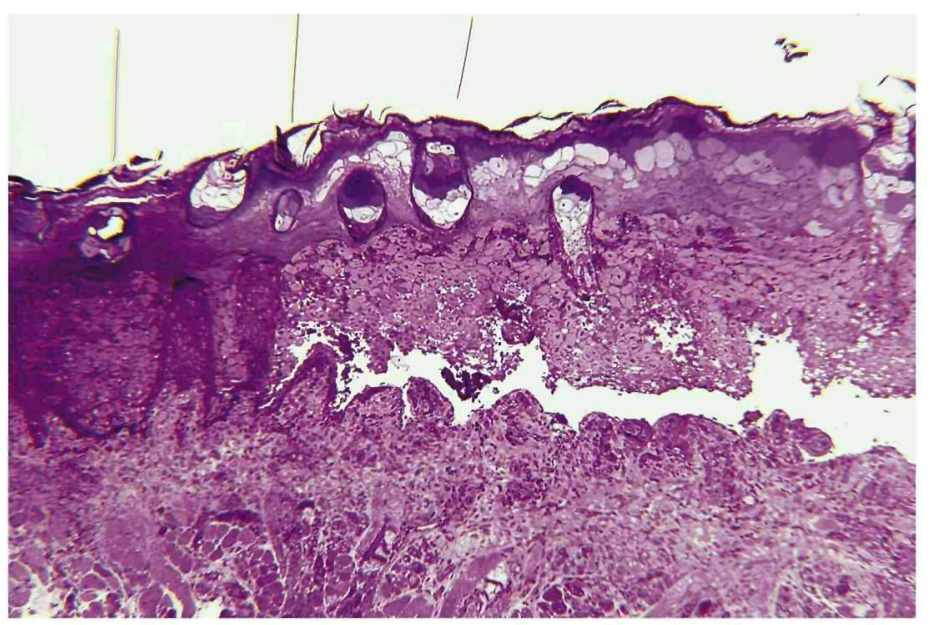

Figure 7: Semi-thin section of foot and mouth disease virus infected tongue. 


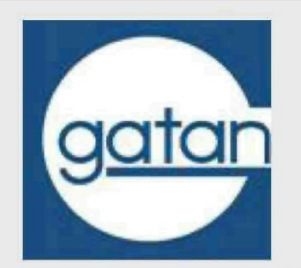

\section{Marketing Analytical} TEM Product Specialist

Gatan, Inc. invites applications for a Marketing Product Specialist position in support of Gatan's Analytical product line. The successful candidate will serve as a "resident expert" on Analytical TEM applications. The typical responsibilities include providing customer support, generating promotional and customer training materials, conducting product demonstrations, and assisting in new product development.

The successful candidate must have a strong background in analytical TEM including EELS, EDS, CBED, STEM, and EFTEM. A Ph.D degree is required with 3+ years experience in hands-on analytical TEM applications. A proven record of analytical TEM application work, including publications is required. Excellent verbal, written, and interpersonal communication skills in English are essential. Basic understanding of electron optics in TEM and energy filters and familiarity with Gatan products (EELS spectrometers/filters, CCD cameras and software) is a plus. Certain amount of travel (20$25 \%$ ) is required.

The position is based in Pleasanton, California and carries a salary commensurate with experience and an attractive benefits package. Please submit your resume (attachments OK) to hr-marketingjob@gatan.com.
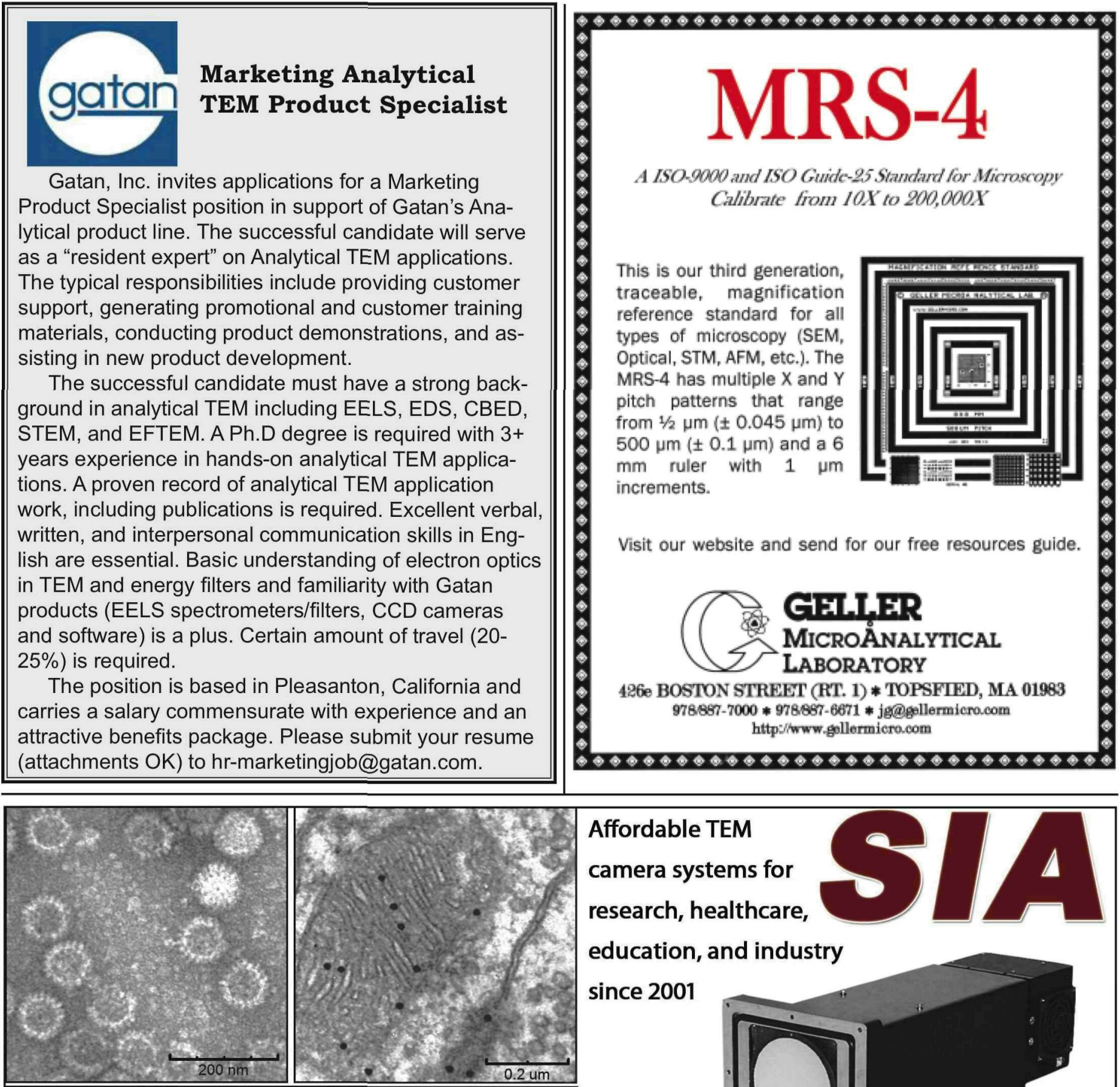

\section{Affordable TEM \\ camera systems for}

research, healthcare,
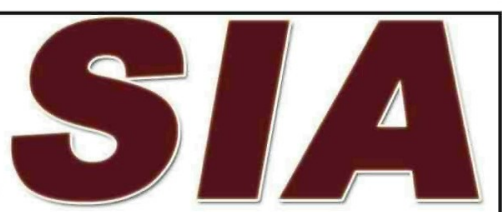

education, and industry

since 2001

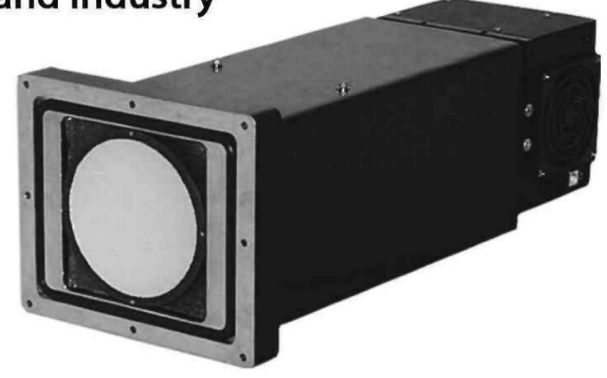

1 to 16 Megapixels, slow scan and TV

Magnification factor of 1 on bottom mounted cameras
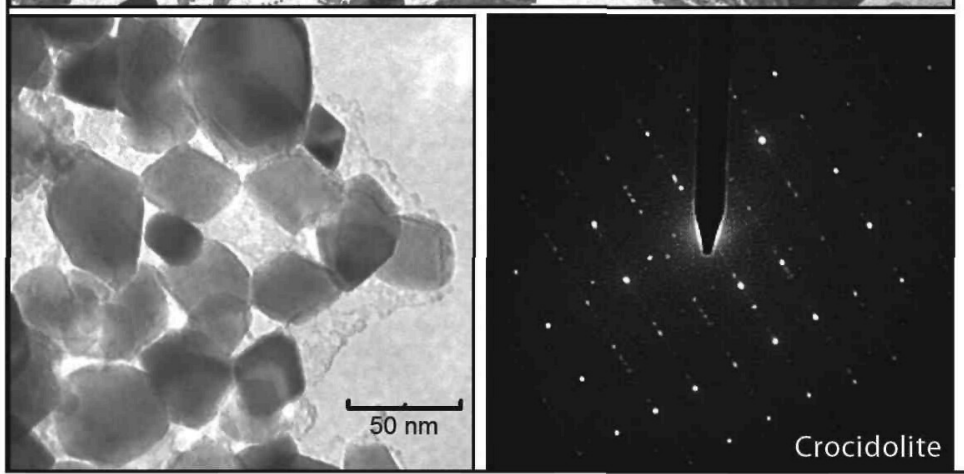

Diffraction beam stop on side mounted cameras

Reliable, easy to use and upgrade

Standard and custom configurations for any TEM

Compatible with existing TEM accessories

Scientific Instruments and Applications 2773 Heath Lane; Duluth, GA; 30096 (770) 232 7785; www.sia-cam.com

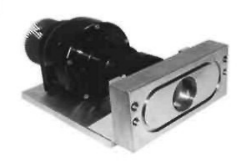




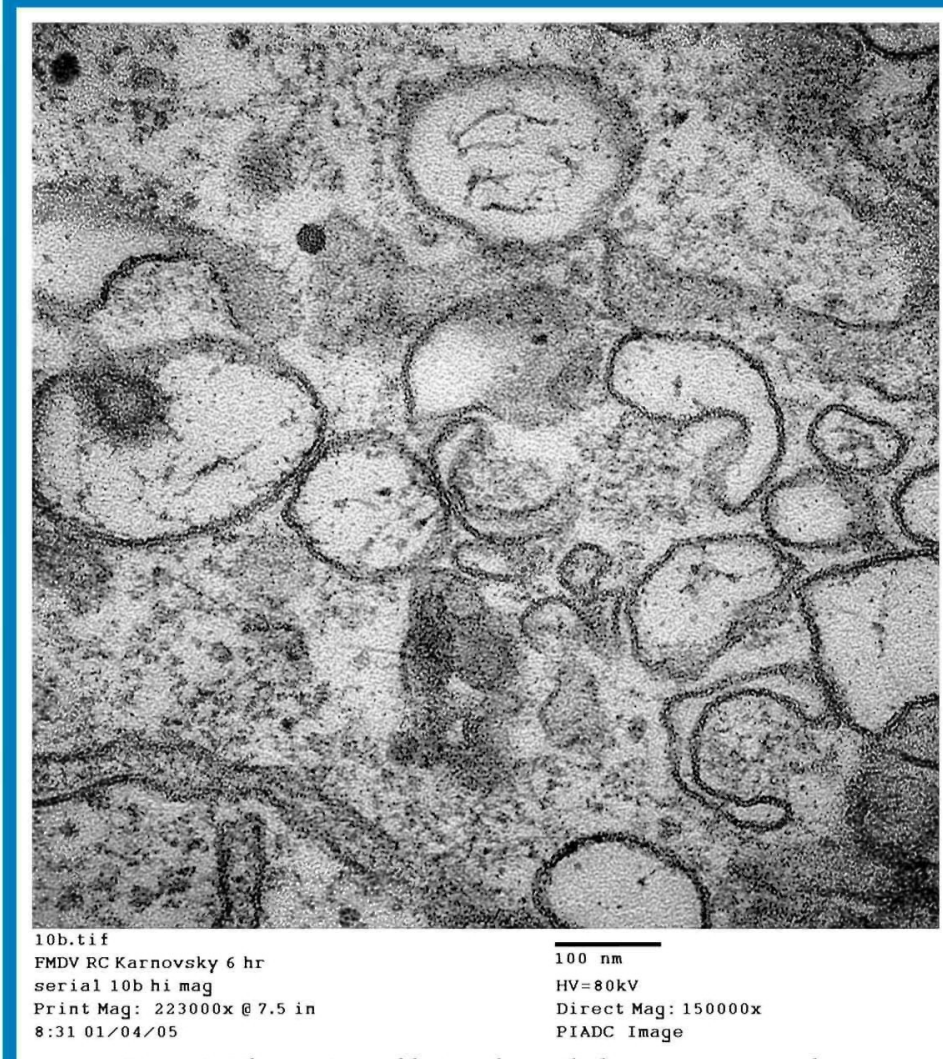

Figure 8: Thin section of foot and mouth disease virus particle.

agnostic assays and validates them for detection of foreign animal disease agents, this group also depends on electron microscopy. For example, expressed proteins from recombinant baculovirus-infected cells provide ELISA antigen for screening sera for anti-FMD virus antibodies. Electron microscopy of one recombinant expressed antigen, non-structural protein $2 \mathrm{C}$, reveals the latter's dramatic interaction with internal cellular membranes of the insect cells producing the protein (Figure 6).

\section{A Fragile Virus Requires Different Protocol}

VCMI provides semi-thin and ultra thin-section analysis of infected cells and tissues for pathology and pathogenesis studies. The
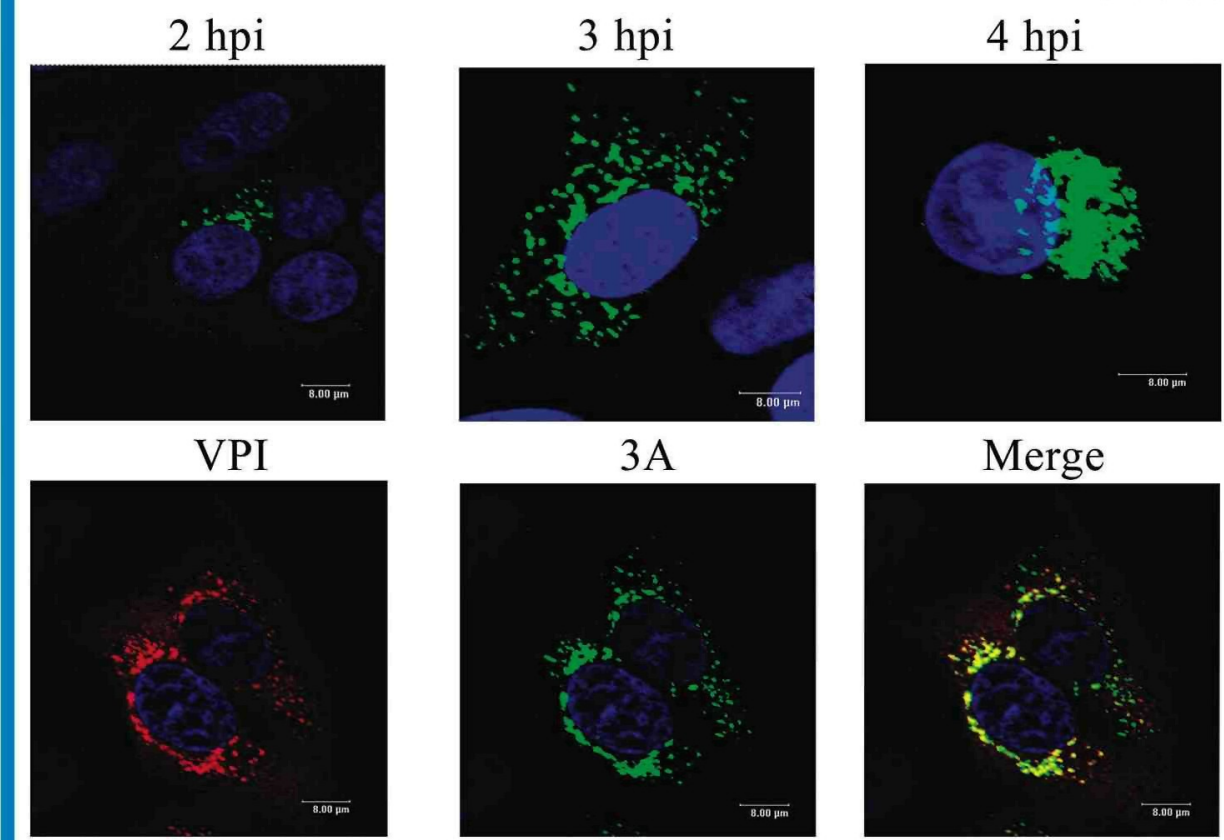

Figure 9: Confocal panel of dual staining of structural and non-structural proteins. host tissue cell response to FMD virus involves changes in specific target epithelial cells, namely kerotinocytes and inflammatory cells (Figure 7). However, understanding the mechanism of virus formation has been hampered by the fragility of the virus with conventional electron microscopy fixation protocols. Microscopists at Pirbright Laboratories, UK, have shown that the virus can be preserved in the cytoplasm using high-pressure freeze-substitution [1]. We have recently used solutions containing high concentrations of aldehydes ( $4 \%$ paraformaldehyde and $2.5 \%$ glutaraldehyde) buffered with $0.2 \mathrm{M}$ cacodylate high at $\mathrm{pH}$ 8.0. Fixing infected cells with this solution, we find hexagonal particles $25 \mathrm{~nm}$ across appearing in close proximity to small ovoid vesicles (described in other picornavirus infections as replication complexes) [2-4] (Figure 8). Serial reconstruction studies are underway to determine the three-dimensional organization of the replication complexes and the potential formation of mature particles.

\section{Confocal Laser Scanning Microscopy}

Observation of cellular distribution of structural and nonstructural FMD virus proteins during replication gives insight into viral assembly. Confocal laser scanning microscopy permits accurate co-localization of proteins (Figure 9). The first set of panels localizes structural VP1 with monoclonal antibody over time and the second set of panels co-localizes the non-structural protein $3 \mathrm{~A}$ and the structural protein VP1.

\section{Transmission Electron, Immunoelectron and Laser Capture Microscopy}

PIADC's ARS group also uses microscopy while applying the latest molecular biology and genetic engineering techniques to develop vectored-vaccines against FMD. Transmission electron microscopy and immunoelectron microscopy are used to determine the state of the antigen produced by the recombinant, non-replicating adenoviruses. Another ARS approach is to use cloned virus to study the immunological and the biophysical properties of viruses with engineered changes to coat proteins to develop potent vaccines. Cell free expression of cloned viruses also allows the study of the virus assembly process that is followed by transmission electron microscopy.

To further aid in microscopic study of foreign animal diseases, $4 \mathrm{hpi} \quad$ VCMI recently acquired a laser capture microdissection instrument that allows for the harvesting of small numbers or even single cells identified by morphology or by immunodetection. These cells are then processed to determine the level of expression of viral and host genes via microarray.

\section{Summary}

Transmission electron microscopy, confocal laser scanning microscopy and laser capture microdissection provide critical support for Plum Island Animal Disease Center's vaccine development, diagnostic testing and pathogenesis and pathology study of high consequence foreign animal diseases. And under these microscopes, the mission of Plum Island Animal Disease Center can be clearly seen.

\section{References}

[1] P. Monaghan, et al., J. Gen. Virol. 65 (2004) 933.

[2] A. Salonen, et al., Curr. Top. Microbiol. Immunol. 285 (2005) 139.

[3] D. A. Suhy, et al., J. Virol. 74 (2000) 8953.

[4] R. C. Rust et al., J. Virol. 75 (2001) 9808. 


\section{Omniprobe Short-Gut tim brings}

\section{HIAI THROUHHPUT \\ to in-situ TEM sample preparation}

In-Situ FIB Lift-Out

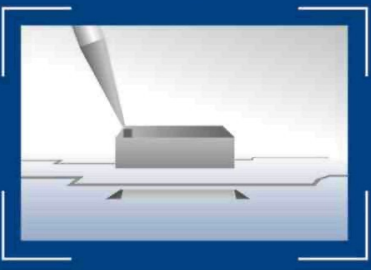

Streamlined in-situ

FIB lift-out with

Omniprobe's

patented Total

Release $^{\mathrm{TM}}$

technology

Mechanical Conversion

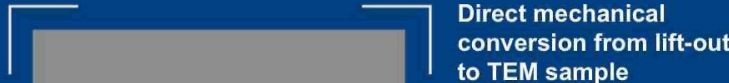

to TEM sample

TEM Sample Prep And

\section{Nano-Mechanical Testing}

The AutoProbe ${ }^{T M} 200$ is a computer controlled in-situ multipurpose nanomanipulator system capable of:

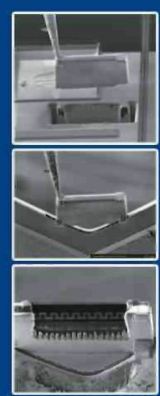

- Lift-out for TEM Sample Prep

- Electrical Measurements

- Nano-Mechanical Testing

Ideal For:

- IC Process Control and

Failure Analyses

- Topographic Surfaces

- Brittle or Soft Materials

- Phase Boundaries

- MEMS Components

$C \in$ and UL certified

Patented Technology

AutoProhe 200
Omniprobe, Inc. 10410 Miller Road Dallas, TX 75238 Phone: $214-572-6800$

Fax: 214-572-6801

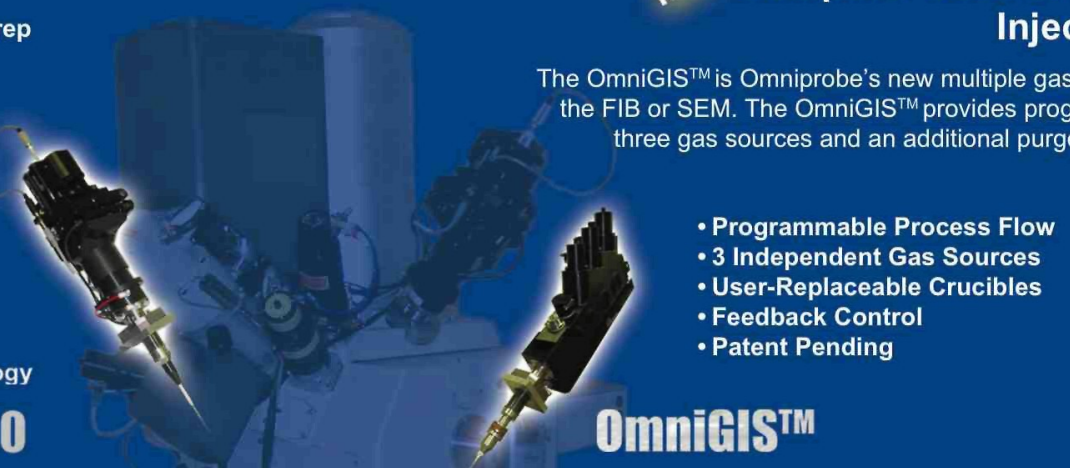

Computer Controlled Multi-Gas Injection System

The OmniGIS ${ }^{\top M}$ is Omniprobe's new multiple gas injection system for

- Programmable Process Flow

- 3 Independent Gas Sources

User-Replaceable Crucibles

Feedback Control

Multiple Gas Sources (Oxide Isolated Pt Via)

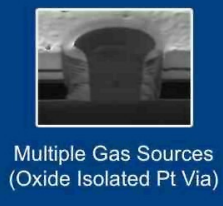

European Support: SEM-FIB Solutions

+441993771203 tony.kendrick@sem-fib.com Oxford, United Kingdom 